\title{
"Yo creo en Colombia", una frase que se creía imposible
}

Andrés Canela*

¿Por qué creer en Colombia, más que expresar una afirmación se ha convertido para algunos colombianos en una gran muralla infranqueable, imposible de sobrepasar y vista por algunos como un reto a vencer por otras personas? Pero este es tan sólo un lado de la moneda, la otra cara la está viviendo el país en manos de personas como Pedro Medina, Gerente General de McDonald's Colombia, quien se ha encargado de construir el programa "Yo Creo en Colombia", buscando hacer un llamado de atención y a la vez empoderar a los colombianos para que hablen bien de su país.

Con frecuencia, el hecho de que cada uno de nosotros no puede hacer mucho por el país es un pretexto para que muchos de nosotros no hagamos nada por él. Con esta contundente frase, Medina ha hecho ver a 18.235 personas que Colombia sí requiere de un cambio, pero que el cambio está en las manos de cada uno de los colombianos.

La charla "Por qué Creer en Colombia", hace parte del programa "Yo Creo en Colombia", liderado por McDonald's y conformado por un equipo de trabajo interdisciplinario que busca día a día nuevos mecanismos para intervenir positivamente en la historia del país.

La iniciativa de crear este programa inspiró a Medina hace ya más de dos años, cuando se encontraba dictando una clase universitaria y vio cómo de un total de 39 alumnos sólamente 12 pensaban quedarse en el país al finalizar sus estudios. Esa cifra lo impactó, pero más se sorprendió cuando trató de motivar a sus estudiantes para que vieran que Colombia no tiene nada que envidiarle a otros países; sus argumentos eran pocos $y$, en ciertos casos, no presentaban una verdadera diferencia; ninguno de los 27 estudiantes de la clase se sintió realmente motivado por sus consideraciones. Fue

Ingeniero, Universidad de Los Andes. entonces cuando surgió la idea de iniciar un proceso de estudio que llevara a demostrar por qué Colombia sí puede ser una alternativa de trabajo, desarrollo y compromiso. Lo que resultó entonces fue una conferencia denominada "Por qué Creer en Colombia", una charla elaborada y conceptualizada por el mismo Medina y un grupo de trabajo de las universidades EAFIT, Javeriana, CESA, Andes y Nacional. Desde ese día la charla comenzó a tomar vuelo y empezó a ser solicitada permanente por universidades, empresarios, Gobierno, gremios, colegios y organismos independientes. Actualmente se ha presentado 99 veces en siete ciudades y tres países.

El compromiso de Pedro Medina con el país se afianzó mucho más y ahora se ve reflejado en el esfuerzo que está dedicando a este programa, pues dedica entre el 20\% y el $30 \%$ de su tiempo a dictar, crear, fortalecer y desarrollar a "Yo Creo en Colombia" y sus charlas. Este dato es sorprendente y, bajo la luz del compromiso social que ha significado grandes reconocimientos para McDonald's mundialmente, Pedro Medina ha visto una gran unidad entre el programa y lo que la empresa que gerencia desea: McDonald's es una empresa reconocida mundialmente por su compromiso social; hemos sido catalogados por la Revista Fortune como la primera empresa en responsabilidad social en el mundo, asegura Medina. La visión de nuestra empresa se centra en la credibilidad que tenemos sobre el país y su gente; somos gente buena y por eso McDonald's ha creado una fuerza de 1.020 empleados y 350 proveedores nacionales, de los cuales algunos ya están exportando a otros McDonalds en el mundo. Hemos anunciado una gran inversión en el país, de 75 millones de dólares, y abriremos en tres años 50 nuevos puntos de venta; nuestra empresa cree en Colombia y por ello el objetivo del programa 'Yo Creo en Colombia" está totalmente alineado con nuestra visión de negocio. 
La principal carta de presentación del programa "Yo Creo en Colombia" es la charla que cristaliza, en tan sólo una hora, una propuesta de cambio, empoderando a las personas para que puedan hablar bien de su país, lo conozcan y se acerquen a aquello que lo hace único en el mundo. Es un llamado de atención para que todos los colombianos se sientan parte del cambio, que reconozcan esa incertidumbre como propia y que evidencien por qué vale la pena cambiar la forma como se habla, se trata y se visualiza al país. El romper paradigmas, el cambiar conceptos, el movilizar a todos los actores sociales, son algunos de los puntos que se resaltan como factores de cambio, por ello a la pregunta final de la charla formulada por Pedro Medina al auditorio: "ustedes qué van a contestar cuando les pregunten que si esto será que se arregla", el auditorio contesta, en la mayoría de los casos y a una sola voz, "Sí, ésto se arregla". Medina inmediatamente interrumpe y dice "No.... esto lo arreglamos", el problema no es de unos pocos, ha sido construido por todos los colombianos y de igual manera debe ser solucionado.

El auditorio finalmente encuentra tres opciones propuestas para iniciar un proceso de cambio:
1. Unirse a algún grupo que esté planteando e implementando soluciones.

2. Formar un grupo propio que proponga e implemente soluciones para cualquier organismo.

3. No hacer nada. Pero entonces no criticar, no quejarse y no obstaculizar las soluciones planteadas por otros.

"Yo Creo en Colombia" se aleja cada vez más de una utopía o una pregunta suelta en un salón de clases, pues bajo el soporte y el liderazgo de McDonald's, el apoyo de un equipo, la formulación de nuevas alternativas como una cátedra estudiantil, el desarrollo de clubes y la movilización de colombianos hacía una actitud positiva de cambio, se está generando una nueva cultura. Se comienza a percibir la idea de que quejándonos y pensando que otros van a hacer nuestro trabajo nada se solucionará. Colombia debe dejar atrás el antiguo concepto de "El que no llora, no mama", y reemplazarlo por "No llore, mame".

\section{¿Cómo generar espacios para construir y no destruir?}

Pedro Medina*

El Alcalde Mockus vislumbra una Colombia donde "Tú vales por tu capacidad de construir y no de destruir". ¿Cómo convertirnos en un país que construye? ¿Cómo romper esa realidad que nos señaló Brice Vagly: en Colombia hay mucho poder para bloquear las cosas, pero poco poder para hacer las cosas? Pensar en una respuesta puede resultar complicado, pero se

Economista. puede dar un acercamiento visto en 10 pasos, en donde la fórmula se aplique con diligencia y perseverancia, para crear ese país empoderado y abierto a trabajar en conjunto:

1. Autoestima colectiva: un primer paso está en construir la autoestima colectiva positiva de Colombia. Colombia es un país adolescente al que llevamos varios años resaltándole lo negativo. Identificando, reconociendo y promoviendo lo positivo, equilibramos la balanza entre el vaso medio lleno y el medio vacío. 
2. Visión: ¿cuál es la Colombia que merecemos, la que deseamos, la que estamos dispuestos a construir? ¿Cuál es nuestra visión para el 2020 ?

3. Construir habilidades: habilidades que nos permitan desarrollar el capital social. Habilidades como romper el hielo con un extraño, relacionarse, construir equipos que funcionan, vender ideas y promover positivamente nuestro país.

4. Empoderar: formar grupos empoderados con una visión compartida y con unas reglas de juego claras. Un principio básico de las Relaciones Públicas es el de que un buen comunicador debe "Saber hacer y hacer saber". Muchas veces nos preguntamos si este principio no iría en línea con el de un gobernante, para quién lo importante es hacer y generar un conocimiento en el entorno para que las personas inicien procesos de contacto, construyendo relaciones que permiten un mayor crecimiento personal, social y económico, con una mayor calidad de vida.

5. Oportunidades: identificar creativamente las oportunidades, generando un consenso mediante el cual se reconozcan cuáles de ellas son de alto impacto y baja dificultad.

6. Dividir la tarea: implementar la segmentación de los trabajo en acciones, fecha y responsables; actuando de manera enfocada y profunda. Construir confianza en esos equipos a través del sentido de victoria, que viene con los logros -pequeños inicialmente y luego grandes -.

7. Romper barreras: castigar los "fouls pequeños", como nos advierte el alcalde Mockus: "si no castigamos los fouls pequeños, el partido se desbarata." El trabajo está centrado en no acostumbrarnos a meternos autogoles.

8. Seguimiento: los líderes, estemos donde estemos, debemos entender que se delega la tarea pero no la responsabilidad.

9. Medir resultados: lo que no medimos no mejora.

10. Fomentar: se deben reconocer los avances, recompensar los logros obtenidos y apoyar el trabajo emprendido por otros.
Con esta, fórmula aplicada de manera gradual y con pasos firmes, podemos generar un mayor compromiso de cada individuo, que a la vez va integrando (como en una cadena) todos los aspectos de su vida. El concepto está encerrado en que es mejor dar que recibir, y que esto genera una sociedad que se conecta entre sí por una meta común.

En Colombia tenemos que fortalecer el concepto de trabajar en equipo, según el cual lo que yo hago puede afectar a los demás, tanto positiva como negativamente. En nuestras manos está apoyar esta construcción conjunta de un nuevo país que busque una meta común. Todos estamos conectados y, como decía un gran pensador: cuando una mariposa mueve las alas, todo el universo se mueve.

\section{Cuando nos falle el plan $\mathbf{A}_{\text {g }}$ debemos tener un plan $B$}

Hace unos años escuche a Rudolph Hommes en una intervención durante la ceremonia de grado en un colegio de Bogotá, en la que le preguntaba a los graduados y a los asistentes, por qué creían ellos que en Colombia sólo habíamos obtenido un premio Nobel. Luego de un gran silencio por parte del auditorio, Hommes empezó a efectuar preguntas y a dar las respuestas. Si mal no recuerdo, decía así:

¿Nos falta inteligencia? No.

¿Nos faltan ganas? No.

¿Es acaso falta de iniciativas? No.

Lo que nos falta es especializarnos más, picar menos y concentrarnos más. Los colombianos nos hemos convertido en expertos para crear estrategias e ideas, idear proyectos y conceptualizar situaciones, pero nuestra habilidad para ejecutar dichas actividades es muy reducida. Invertimos gran parte de nuestro tiempo en generar excusas para disculpar nuestra falta de ejecución. Tenemos la tendencia a pensar primero en un "lo que pasa es que..." antes de contestar con un "qué pasaría si...." Entonces podemos tomar como ejemplo el caso de una empresa que está desarrollando en medio de los llanos orientales (un territorio de suelos ácidos) cultivos de mazorca, algo que parecía imposible. Ellos pensaron en un "qué pasaría si..." 
El punto, entonces, se centra en cómo lograr que nos convirtamos en gente que no sólo promete, planea, idea, vislumbra, sino que también ejecuta. Pues la solución resulta muy sencilla. ¿Por qué no empezamos por idear y proyectar acciones que sean factibles de desarrollar, o en las cuales nos podamos comprometer? Tomemos el ejemplo de los frentes de seguridad ciudadanos, que viene liderando la Policía Nacional desde hace ya seis años y de los cuales existen más de 5.400 funcionando. A través de actividades como ésta puedo intentar el desarrollo de un programa de cambio que involucre a mi comunidad más cercana con los vecinos. En vez de imaginar una gran iniciativa, cuyo cumplimiento sea poco factible, debo comenzar por trabajar sobre acciones reales en las cuales contaré con el apoyo de dicho grupo.

Bajo esta perspectiva, tenemos que iniciar un proceso en donde descubramos y reconozcamos que las acciones difíciles no son necesariamente las de mayor impacto. Para muchos saludar al vecino, conocer el nombre de los porteros o saludar en la calle, pueden parecer acciones inoficiosas y ridículas, pero el impacto que esto tiene sobre el comportamiento social de los individuos, el acercamiento que genera y el afecto de valoración por los otros, son muy altos, tal vez más que cualquier otro tipo de acciones.

Nuestro plan A no necesariamente debe ser el más difícil, pero sí puede estar apoyado por pequeños subplanes que ayudan a generar actividades de cambio. Hace unos años los bogotanos salíamos a otras ciudades del país y llegábamos impresionados por la amabilidad de las personas, su grado de afecto y preocupación en el trato con los demás. ¿Cuál era en ese entonces la diferencia con Bogotá? Simplemente que la gente tenía por costumbre saludar y despedirse en los almacenes, las calles, los parques y, en general, en todos los lugares. Bogotá ha creado con las últimas alcaldías una cultura similar, en la que se ha buscado que los habitantes de la capital sean más amables con los otros. ¿Qué hemos conseguido? Una ciudad menos agresiva y que se encuentra en un proceso de cambio. Los capitalinos aprendimos algo muy sencillo que nos habían enseñando nuestras ciudades vecinas.

¿Cuál era el plan A de Bogotá?: disminuir la violencia en la capital. ¿Cuál fue el plan B?: desarmar a todos los bogotanos en su lenguaje y en su trato. Existió un plan A y uno B: el segundo ha surtido efecto positivo para generar resultados en el primero. Todos podemos montarnos en el caballo de la confianza e iniciar procesos de cambio que son aparentemente leves, pero que pueden ser el plan B de una gran idea común como la paz (plan A).

En un artículo anterior escribí esta frase que aún, me parece, tiene validez: con frecuencia, el hecho de que cada uno de nosotros no pueda hacer mucho por el país es un pretexto para que muchos de nosotros no hagamos nada por el país. Invito a que dejemos las excusas y empecemos a trabajar por una nueva $\mathrm{Co}-$ lombia, un nuevo país que necesita gente que se proyecte con pequeñas y grandes ideas, con planes A y B, que generan cambios, que fomentan un interés y una transformación común. Si no escogemos proponer, veremos cómo otros proponen por nosotros, y si no participamos en las ideas de otros no tendremos la posibilidad de criticar constructivamente, opinar y fomentar nuevas iniciativas.

\section{Dejemos salir el argentino que hay en cada uno de nosotros}

La semana pasada fui invitado por el Fondo Cultural del Café, la alcaldía de Manizales y la Gobernación de Caldas, para dictar la charla "Por qué Creer en Colombia" en Manizales. Cuando me encontraba frente a 400 jóvenes, con la primera fila del salón ocupada por los altos empresarios de la ciudad y el alcalde de Manizales, pedí el favor de repartir unas hojas que suelo entregar a los asistentes en mis charlas. Al solicitar la colaboración del público, dos jóvenes se apresuraron a ayudarme, y de igual manera lo hizo el señor alcalde, Germán Cardona. Lo que me sorprendió en ese momento fue cómo el alcalde estaba comprometido en una actividad que en realidad no le competía; no estábamos esperando que él nos colaborara, pero su interés por el tema era tal que así lo hizo.

Lo que para muchos pasó desapercibido, para mí fue un gesto que demostró un elemento que se está convirtiendo en un diferenciador de la nueva Colombia. El alcalde, muy acomedidamente estaba, ofreciendo el 
apoyo a una actividad en la cual estaba comprometido; él no tenía por qué esperar a que otras personas actuaran en su nombre y no safó la situación en otras personas sino que la asumió como propia.

¿Cuántos de nosotros dejamos de hacer acciones que nos parecen muy sencillas por miedo al qué dirán? El compromiso que estamos acostumbrados a generar con ciertas acciones a veces se queda corto y no lo asumimos como propio, pero eso debe cambiar. Los colombianos estábamos convencidos de que alguien iba a hacer algo por resolvernos la situación nacional, pero nos hemos dado cuenta de que somos nosotros los que debemos cambiar y actuar si queremos evidenciar un nuevo país.

Miremos un ejemplo reciente de esto que tocó la fibra de la mayoría de colombianos: David Letterman, en su programa "The Late Show", hizo un comentario que sugería que a las reinas de belleza no las iban a calificar por su belleza sino por sus aptitudes como, por ejemplo, a la Señorita Colombia, que se destacaba por su capacidad para ingerir condones llenos de cocaína. Este sarcasmo llevó a que la comunidad colombiana residente en Nueva York reaccionara contra el programa y la cadena CBS. Pero también llevó a que la Señorita Colombia obtuviera una entrevista por más de diez minutos en el programa de Letterman. Una situación que en un principio parecía adversa se transformó en una oportunidad para hablar bien de nuestro país, una imagen que duró grabada en la mente del famoso comediante durante tres programas seguidos. La actitud de la Señorita Colombia demostró al mundo su compromiso con la imagen positiva del país, y que no permitiría que nadie se refiriera a él de manera negativa, pues al agredir a Colombia la estaban agrediendo a ella. Noceti nos demostró a todos los colombianos que el tema de tratar bien al país, y defenderlo cuando es necesario, es algo que sí nos toca, y nos toca a todos.

Estamos frente al fin de un paradigma como el de "eso no me toca a mí". Los colombianos estamos entendiendo que los asuntos sí son con nosotros y que, por lo tanto, debemos asumirlos como asuntos personales buscamos un mismo fin: reconocernos como gente buena, como un país compuesto por personas buenas, que trabajan por el beneficio de Colombia y de los colombianos.
Tenemos que acostumbrarnos a hablar bien de nosotros mismos. Cuando nosotros hablamos bien de nosotros mismos son muchos los ojos que se centran en nuestras ideas, pero cuando hablamos mal y despectivamente el país estamos hablando mal de nosotros mismos y estamos alejando la atención de la gente. ¿Por qué no intentamos hacer el ejercicio de los argentinos, quienes a todo momento se están echando flores, se están reconociendo como únicos, como buenos, y están continuamente construyendo una autoestima colectiva positiva? Día a día están poniendo un ladrillo sobre su estructura de confianza. Colombia necesita "sudar la camiseta", y que nos montemos todos en la selección de la buena confianza.

\section{Estamos pintados sobre una nueva Colombia}

En 1999, cuando dictaba una clase en una universidad de Bogotá, pregunté a mis alumnos cuántos de ellos pensaban quedarse en el país al cabo de cinco años; de un grupo de 39 estudiantes sólamente 12 levantaron la mano. Al ver esto les pregunté a los 27 restantes por qué no se quedaban, y me devolvieron la pregunta: Pedro, ¿díganos por qué quedarnos? Si escribiera la respuesta que dí en ese momento, muchos de ustedes no verían mayores razones para estar en el país. Fue un momento muy frustrante como profesor y como colombiano, pero a la vez fue un momento en el cual un nuevo proceso nació. Conformé un equipo de 50 estudiantes de cinco universidades y montamos una charla que ha evolucionado y hoy en día, en tan sólo un año, ha alcanzado a más de 20.000 personas en siete ciudades y tres países.

Con la idea de empoderar a los colombianos para que hablen bien de nuestro país, me he encontrado con grandes barreras que nosotros mismos no queremos derribar. Hemos asumido posiciones cómodas que, sin darnos cuenta, se han convertido en hábitos y en costumbres que ya relacionamos directamente con nuestra idiosincrasia: "Por eso estamos como estamos", "es que eso es típico de los colombianos", "claro, ese tenía que ser colombiano" y "ahí estamos pintados", son frases que escuchamos frecuentemente en un día. Pero que pasaría si en lugar de ver el vaso medio vacío lo vemos 
medio lleno. ¿Estamos preparados para ver esa realidad y no un panorama oscuro o negativo? Antes de contestar veamos lo siguiente:

Tenemos gente trabajadora, creativa, capaz, educada y comprometida; basta mencionar a Andrés Jaramillo Botero, experto mundial en nanotecnología y uno de los 2000 científicos más importantes del Siglo XX. Gabriel García Márquez, premio Nobel de literatura y récord mundial de ventas de un libro (32 millones de copias). María Isabel Urrutia, una telefonista de Cali que tuvo un sueño sin precedentes en la historia suramericana de los juegos olímpicos, ganar la medalla de oro olímpico en pesas, y a punta de trabajo duro, creatividad y compromiso lo consiguió.

Los anteriores son sólo tres ejemplos, pero ahora podemos resaltar que somos el cuarto productor mundial de agua, tenemos seis veces más que el promedio mundial y tres veces más que el latinoamericano; somos el cuarto productor de ferroníquel (materia prima para los microchips y estamos en la era de los computadores), y todos estos recursos nos dan ventajas competitivas frente al mundo. Somos el primer país en biodiversidad por metro cuadrado (grandes oportunidades en biocomercio), pero aún así podríamos seguir pensando "que los colombianos ahí estamos pintados". Yo diría que sí, que sí estamos pintados dentro de un gran cuadro que se llama Colombia, un país que tenemos que empezar a reencontrar, a conocer y, lo más difícil, a apropiar. Por qué no pintar esa nueva Colombia y ponerle colores positivos. Comencemos rompiendo el paradigma "ahí estamos pintados".

Ahora pregunto nuevamente ¿estamos preparados para ver una realidad distinta? Sería engañarnos negar los problemas de nuestra patria, pero cuando nos enfocamos en el problema nuestra mente se bloquea y se frustra; cuando nos enfocamos en lo positivo potenciamos ese gran motor que tenemos los colombianos.

\section{¿Las malas noticias sí venden?}

Durante los dos últimos años, tiempo en el cual he venido trabajando en el programa "Yo Creo en Colombia", he logrado detectar en los medios de comunica- ción del país grandes noticias que han significado nuevos retos para nuestra sociedad, nuevas oportunidades y nuevas posibilidades de crecimiento. Esto es muy emocionante, pues he visto cómo hemos dejado de ser un país "paria”, para convertirnos en un país que interesa a la comunidad internacional por múltiples razones (más allá del conflicto armado). Pero tengo que reiterar que dichas noticias hay que saberlas detectar, pues el país y los colombianos aún no estamos preparados para creer en lo bueno y no prestar atención a lo malo. Nos cuesta trabajo creer que la primera página del periódico no tenga noticias sangrientas o violentas, y estamos dejando de lado lo positivo.

¿A qué se debe este fenómeno? Las noticias malas en un momento histórico del país se convirtieron en una gran posibilidad de vender, de lograr que los noticieros fueran vistos, las radios prendidas y los periódicos leídos. Las malas noticias comenzaron a atraer ese sentimiento de "morbo" innato a la raza humana; nos gustaba oír sobre las tragedias y los males ajenos. Este concepto llevó a que las noticias tuviesen este valor por su carga negativa, perjudicial, acusativa, escandalosa, coyuntural y dramática. Lentamente nos adaptamos a ese modelo bajo el cual vivimos actualmente.

¿Pero es esa la realidad actual? ¿Estamos dispuestos a ver noticias negativas y violentas? El paradigma de que la noticia mala es la que vende se está rompiendo. Los colombianos estamos reaccionando y estamos evidenciando una nueva evolución en el mundo noticioso, estamos apartándonos del amarillismo y estamos empezando a generar espacios en los cuales volvemos a hacer noticia nuestros valores, nuestros superlativos, nuestros diferenciadores y nuestra gente.

La información que nuestros medios de comunicación emiten de nuestro país es, simplemente, el reflejo de lo que los colombianos estamos destacando como elementos noticiosos de nuestra realidad y nuestra cultura. ¿Acaso somos un país compuesto por una fuerza armada de 40 millones de personas? ¿Estamos cometiendo actos vandálicos en cada esquina? ¿Nos asesinamos por discusiones triviales? No desconozco que estos elementos estén inmersos en nuestra patria, pero no son los puntos que hacen que todos los días un país entero se levante y busque alternativas de cambio. 
Estamos en un proceso de transformación y la manera como nos alimentamos informativamente debe cambiar también, se debe ajustar a ese nuevo país que estamos construyendo, un país positivo, orgulloso y único.

El mundo ha cambiado su percepción acerca de Colombia. Miren cómo nos está vendiendo una agencia de viajes francesa:

"Si usted quiere conocer el Caribe vaya a Cuba o República Dominicana,

si quiere conocer el Océano Pacífico vaya a Chile, si quiere conocer la Cordillera de los Andes vaya a Ecuador,

si quiere conocer la Selva Amazónica vaya a Brasil, si quiere conocer las Culturas Precolombinas vaya a México o Perú,

Pero si quiere ver todas esas cosas reunidas, vaya a Colombia".

¿Somos concientes de ésto? ¿Lo estamos anunciando? ¿Nos lo estamos vendiendo? No. Las noticias malas no venden más que las buenas. Todo se reduce a lo que queramos ver día tras día, la solución está en nuestras manos y la demostración de que este cambio se está dando lo he evidenciado a través de la charla que dicto, conocida como "Por qué Creer en Colombia". Durante este año ha llegado a más de 24.200 personas, en 12 ciudades y 3 países, con un total de 119 presentaciones a la fecha y una programación a fin de año de 82 charlas más. Los colombianos queremos cambiar y estamos dejando de lado las malas noticias por las buenas. Hablar bien de Colombia nos está dando resultados.

Usted es dueño de su tiempo, lo que lee, lo que oye y lo que ve, así que a las malas noticias, simplemente “apague y vámonos", esa es la nueva onda.

Los colombianos somos buenos negociadores, pero como país ¿somos buenos vendedores?

La semana pasada, al finalizar una charla en Bogotá, se me acercó una mujer y me dijo que ella sí tenía las intenciones y la voluntad de hacer cosas por el país y por su comunidad, pero que no sabía como canalizar esa energía, no sabía como guiarla, que ella creía que no podía hacer nada. Mi respuesta se dividió en dos partes: la primera fue explicarle que ya era un gran ade- lanto que estuviese pensando en realizar un cambio, pero que no debía pensar que sus oportunidades estaban limitadas; en Colombia existen 7.200 fundaciones sin ánimo de lucro, y existen miles de formas de vincularse a ellas, lo que nos falta es saber cómo nos vendemos a nosotros mismos, identificar nuestras fortalezas y construir gestión empleando esas habilidades.

El colombiano es reconocido internacionalmente como un excelente trabajador, leal, inteligente y emprendedor. De hecho tenemos miles de casos exitosos por fuera del país trabajando en grandes posiciones, como el caso del vicepresidente mundial de ventas de Microsoft Corporation, un bogotano egresado de la Facultad de Administración de Empresas de la Universidad Jorge Tadeo Lozano. El punto no es si somos o no capaces, el punto es cómo estamos negociando con nuestras capacidades, nuestra imagen y nuestro país.

Claro ejemplo de nuestra capacidad es el que se presenta cuando uno habla de la más importante negociación de la Cámara de Comercio Internacional, entre Andersen Consulting y Arthur Anderson, un conflicto de un billón de dólares que fue mediado por un colombiano. Así mismo, vimos cómo hace pocos meses vino al país una delegación del gobierno alemán para aprender de nosotros sobre la evolución de temas para el manejo de los conflictos entre la juventud. El resultado de esto fue que dicha delegación regresó al viejo continente con cinco programas, entre los cuales se destacaba el de fútbol en las calles desarrollado por la alcaldía de Medellín.

La pregunta entonces sería si los colombianos somos o no buenos negociadores, buenos vendedores. Yo creo que hay grandes ejemplos de que sí lo somos, pero hay que seguir unas pautas para que esto se vuelva un común denominador. Tomemos el caso de las exportaciones, en el que existen cuatro reglas básicas:

1. Uno debe aprender a venderse a sí mismo.

2. Debe aprender a vender el país en el que vive.

3. Se debe saber vender el producto.

4. Garantizar siempre que la idea de la exportación está ligada a un servicio que diferencie. 
Vemos cómo bajo estos cuatro puntos se empieza a filtrar el famoso concepto de beneficio, en donde lo que yo estoy ofreciendo es un beneficio que debe girar en torno del otro. El beneficio de mi producto debe ser representativo para mi comprador, debe ir en torno a su dirección y presentarle algo novedoso que él no tenga, que le haga falta o que lo complemente. Así mismo, debemos empezar a visualizar claramente que un comprador no toma su decisión por lástima.

Teniendo lo anterior en mente, ¿cómo nos estamos vendiendo? ¿cómo estamos vendiendo nuestro país? La estrategia no puede continuar bajo la lupa de la lástima internacional. De hecho, ese paradigma se ha roto y la comunidad internacional nos está viendo, pidiéndonos asesorías, y estamos prestando asistencia mundial en muchos frentes.

Volviendo al principio, y siguiendo bajo la pregunta de la señora que se me acercó a la salida de una charla, yo creo que el punto no es tener en dónde actuar para ser un agente de cambio, sino saber desde dónde puedo yo hacer algo para generar dichos movimientos. Un buen negociador muchas veces no ejecuta, pero sabe cómo hacer conexiones para la buena ejecución de un plan. Por éso, si se tienen buenas ideas, podemos iniciar por proponerlas a un grupo o una persona, iniciar un proceso de mediación y de negociación, con el único fin de motivar a otros y generar un cambio.

Negociar no significa ceder o dejar de lado los intereses para beneficiar a otros; tenemos que cuidar ese doble sentido que le ha dado nuestra cultura a dicha palabra. Mediemos más, negociemos, fomentemos puntos de encuentro, promovamos el intercambio de ideas, y motivaremos las acciones y su ejecución.

\section{Muchos ponis en medio de la boñiga}

Hace unos días me encontraba montado en un teleférico en el Parque del Café en compañía de Diego Arango, el director-fundador del parque, y Rodrigo Estrada, Presidente de la Cámara de Comercio de Armenia, y le pregunté a Diego de dónde salió este teleférico y él me contó la historia.
Estaban construyendo el Parque del Café y soñaron con un teleférico. Se pusieron a cotizarlo y se encontraron con que costaría 4 millones de dólares. Diego obtuvo una cita con el presidente de la compañía de teleféricos, se sentaron, miraron los catálogos, conectaron y construyeron una relación, y en ese momento Diego le preguntó a este norteamericano: “Cuente, no tiene un segundazo?" y el otro no le entendió y por fin de explicarle la palabra "segundazo" lo entendió y se rió. Se pusieron a investigary en la ciudad de Knoxville, Tennessee, descubrieron que en una pasada feria mundial había un teleférico que estaba desmantelado y abandonado. La empresa le ofreció a Diego el teleférico en 300 mil dólares, y por 350 dólares más lo dejaron como nuevo, instalado en Armenia, totalmente refaccionado y reconstruido.

Cerrando la negociación, Diego logró que por mil dólares más le encimaran un carro de bomberos de principios de siglo, también en perfecto estado, que ahora se encuentra en el Parque del Café.

Aquellos que han visitado el Parque podrán corroborar lo siguiente: no conozco un parque temático en las Américas que inspire más que el Parque del Café, más allá de los bambúes y del show robotizado de orquídeas, de los caminos ecoturísticos y la montaña rusa más grande de Latinoamérica, de aquellos exquisitos patacones y la cultura de servicio de la gente; un parque que representa la Colombia que no se rinde, que cree en sí misma, este país que está dispuesto a romper todos los paradigmas y a reconstruir su presente y vivir su futuro como lo merece.

La economía cíclica generada por la dependencia del café volvió al Departamento del Quindío una región muy vulnerable, como le sucedió cuando vino la crisis del grano. Dicen que de cada crisis salen oportunidades, y claramente salió de ahí la idea de hacer un desarrollo agroindustrial y un desarrollo turístico. ¿Por qué esto? Pues sencillamente la industria del café, que ha sido tan importante para Colombia, y el Comité de Cafeteros, se habían dedicado a hacer desarrollos en infraestructura de servicios en el Departamento y todas las fincas contaban con acueducto, energía y servicio telefónico. Las carreteras intermunicipales y veredales eran pavimentadas. 
En el año 1996 había 143 fincas dedicadas al agroturismo y el ecoturismo en el departamento del Quindío, y en la actualidad llegan a 300. Este Departamento es pionero en el Pacto Andino en parques temáticos y tiene el único parque de todo el mundo en su género, el café. Si pensamos en la cultura del este delicioso grano, una cultura que toca los temas de química, botánica, geografía, arte, gastronomía, música, tradiciones orales, arquitectura, ingeniería, amor, transporte, medicina, salud, ingeniería genética y entretenimiento.

Para montar el Parque del Café no había punto de referencia, no existía lo que se conoce como el bench mark; había un equipo reducido, recursos limitados, pero había mucha pasión, la de un gran soñador, Diego Arango; que soñó con el parque, y que junto a un admirable equipo de trabajo lo hizo realidad. El Parque del Café ha logrado en el primer año 270 mil visitantes, y en este momento mantiene entre 300 y 400 mil al año. En la última temporada de fin diciembre-enero visitaron el parque más de 100 mil personas. El éxito ha permitido desarrollar dos parques adicionales: Panaca y el Parque de las Mariposas. Con el Jardín Botánico de Calarcá han permitido generar una industria de turismo y ecoturismo en el Departamento haciendo que toda una raza pujante de cafeteros se valga por sí misma, que luche por su propio destino y convierta al Quindío, como lo han hecho, un departamento que antes sólo era cruce de carreteras, en el segundo destino turístico del país, el cual ha generado nuevos proyectos que ya vienen en camino: el Parque de los Artesanos de Tebaida, que va a ser una sociedad empresarial; el Parque de Safari Marabelez, de la Tebaida, al estilo de Bush Gardens en Tampa; el megaproyecto del teleférico de alta montaña del Parque Nacional de los Nevados, y algunos sueños adicionales que cuando ustedes vayan al Quindío se los comentarán.

Si todos en Colombia pensamos en un instante en todas las razones, los valores $y$, sobre todo, en la gente que trabaja a diario por hacer de este país una nación ejemplar, nos llevaríamos la grata sorpresa de que tenemos innumerables motivos de orgullo como el Parque del Café, en honor a una actividad de vital importancia no sólo para Colombia sino para la economía mundial. Aquí por fin hay un parque que resalta toda la importancia de ese grano que tantas cosas buenas nos ha dado.

\section{Quién es el vivo y quién el bobo}

"El vivo vive del bobo y el bobo vive de su mamá." Con esta expresión, un magnífico jefe cartagenero que tuve la oportunidad de conocer, nos instaba a no dar papaya, a ser productivos, a adelantarnos a las circunstancias. Claramente es importante que utilicemos nuestra malicia indígena y esa viveza que nos caracteriza para producir soluciones, para crear alternativas, para resolver problemas. Sabemos que el problema de Colombia no es la falta de recursos sino la mala distribución de éstos.

Pero algunos han empleado este paradigma para justificar sus trampas, sus chanchullos, sus robos, su falta de honestidad. Argumentan, en su mente o con los demás, que si todos hacen trampas no serán los únicos bobos que no las hacen; inclusive en la costa tienen un dicho "marica el último", para justificar cualquiera atajo que uno tome para llegar de primero. El problema de los atajos falsos, como éstos es, que todo en la vida es como un bumerán; uno lo lanza, avanza lejos y se pierde de vista. Al rato el bumerán regresa por detrás y le pega a quién lo lanzó en la nuca tumbándolo al suelo.

Hace algún tiempo tuve la oportunidad de conocer a un ex procurador de Colombia y le pregunté: ¿por qué es que los colombianos somos tan ladrones? Él me respondió con una pregunta: ¿a qué se refiere? Le dije que nos robamos todo: las cobijas de los aviones, los ceniceros, los avisos de las calles; seguí argumentándole y le comenté que hasta en McDonald's nos han robado bizcochos de los inodoros. La respuesta de él me dejó huella. Me dijo: "nosotros no somos ladrones, sino que decimos que somos ladrones y por eso nos volvemos ladrones". Claramente, si a un país adolescente se le dice ladrón y le reforzamos esta autoimagen, se vuelve ladrón; si le decimos corrupto se vuelve corrupto, si le decimos chanchullero se vuelve chanchullero.

Vimos hace un par de años que algunos medios publicaron la noticia de que Colombia estaba entre los tres países más corruptos del mundo. Esta noticia se basó en una investigación juiciosa. Pero la investigación se hizo sólamente en 50 países, de 184 que forman parte de las Naciones Unidas y unos 70 países 
adicionales en el mundo. O sea que el estudio fue en una quinta parte del mundo.

Recientemente nos metimos en la página web de Transparencia Internacional, y Colombia está en el puesto 41 entre 91 países en corrupción. Seguimos teniendo un problema grave porque todavía algunos piensan que el bien particular es más importante que el bien común. Pero vamos mejorando a pasos agigantados.

Ve uno a los colombianos usando el paradigma de que "el vivo vive del bobo y el bobo vive de su mamá", en unas formas más constructivas. Por ejemplo, he observado en las filas que la gente denuncia a quien se está tratando de colar, observa uno que la gente denuncia la corrupción, observa uno que la gente le pita al que bota basura a la calle, observa uno pactos de transparencia de las empresas de tecnología que hacen negocios con el gobierno, observa uno que los empresarios tienen códigos de ética que firman todos los empleados.

Pedro Gómez, en la inauguración de la nueva facultad de empresas de la Universidad del Rosario - la FAEN - dijo: " mi generación recibió un país pobre pero honrado y está entregando un país empobrecido y corrupto." En la Colombia que nos merecemos, esa Colombia nueva que la crisis nos ha dado la oportunidad de construir, usaremos nuestra viveza para construir y para generar riqueza, en lugar de extender pobreza. Somos un país rico en recursos, en gente, en inteligencia, en energía, en creatividad, en territorio, en comida, en folklore, en cultura, en sueños, y en posibilidades. Manejemos la mentalidad de la abundancia.

\section{Trabajar, proponer y actuar, prioridad sobre llorar}

Como todo el país y todos los colombianos, el 11 de septiembre en la mañana me impactó sobremanera la forma como el mundo fue atacado por el terrorismo y la violencia. Dejando de lado las inclinaciones políticas, económicas o afectivas, nada pudo ser más impactante que haber visto cómo dos vuelos comerciales se estrellaban contra uno de los símbolos más reconocidos por el mundo entero: las torres gemelas. La calma se convirtió en pánico y la tranquilidad en un sentimiento mundial de impotencia.
Pero, por encima del catastrófico evento, hubo algo que me sorprendió aún más y fue apreciar cómo los norteamericanos reaccionaban ante un hecho sin precedentes en su historia: cómo toda una población asumía inmediatamente una actitud de rechazo, solidaridad y respaldo a los estamentos gubernamentales. El impacto de una muerte y un acto vandálico, se tornó en un fuerte repudio y una unión social generalizada.

Vimos, entonces, que en Estados Unidos el pueblo, además de lamentar los hechos, inició un trabajo de solidaridad; donando sangre, ayudando a los cuerpos de rescate, brindando información, prestando una actitud de colaboración en todo momento. Las quejas y lamentaciones se dejaron de lado para pasar a la acción. Me hice entonces varias preguntas tratando de aplicar esta experiencia a nuestra realidad: ¿Qué puede uno aprender de situaciones así? ¿será que los actos de violencia en Colombia ocurridos durante los últimos años, sumados todos, no serán más graves que lo ocurrido el fatídico martes 11 ? ¿cómo lograr el sentido de urgencia que produce una crisis, aquí en Colombia?

Es cierto, 40 años de guerrilla y más de un millón de muertos en 50 años nos han podido convertir en seres inmunes a los actos vandálicos, pero también es cierto que nos hemos vuelto un país quejumbroso y adolorido en todo momento. Nuestro paradigma "el que no llora no mama", se convirtió en una realidad que se integró a nuestra personalidad y a nuestra idiosincrasia. Antes de realizar una acción, nos estamos quejando, nos estamos lamentando sin haber intentado, y si intentamos lo hacemos maldiciendo por habernos metido en el desarrollo de esa idea. Más grave aún, si alguien actúa lo destruimos con nuestra crítica.

¿Qué sucede entonces? Somos sin querer gente negativa. Nuestro nuevo comportamiento debería estar conducido por una nueva idea presentada por Ignacio Orrego, "No llore, mame". Seamos gente que no espera sino que actúa, seamos colombianos al cien por cien, colombianos que sienten su país y que lamentan los actos terroristas, las dificultades sociales y económicas, pero que también reconoce que el cambio está en multiplicar nuestras manos y que la forma de lograr un avance no está en quejas o reclamos, disculpas o excusas, sino en acciones y respuestas. Con frecuencia, el hecho de 
que cada uno de nosotros no pueda hacer mucho por el país es un pretexto para que muchos de nosotros no hagamos nada por el país.

¿Por qué no intentamos hacer un cambio en nuestra forma de actuar? Son muchas preguntas y las respuestas no las encontraremos en libros o en discursos políticos; las respuestas están en las bocas de cada uno de nosotros como colombianos. Así como repudiamos los actos terroristas que afectaron a los estadounidenses, deberíamos hacer, actuar, proponer e implementar procesos de cambio en cualquier sector social nacional y no empezar una acción con la frase típica de "eso para qué lo hacemos si desde aquí no podemos cambiar nada".
Miremos cuántos individuos transforman su comportamiento a partir de la acción propuesta por una persona, un grupo u organización; hemos evidenciado este cambio en los americanos que, trabajando y esforzándose por superar un evento de crisis, han reaccionado y están trabajando en reconstruir. Es cierto; están mirando sus problemas y lamentando los acontecimientos; pero a su vez están siendo guiados por un sentimiento de fortaleza, de no dejarse vencer y de mirar el futuro previendo que estos actos no vuelvan a ocurrir. Tenemos que aprender de los demás y creo, como colombiano, que esa capacidad de reacción, evaluación y solidarización debería ser un ejemplo para nosotros, un país que necesita reaccionar, evaluar y solidarizarse; y que definitivamente necesita llorar menos y mamar más.

\section{FUNDACIÓN UNIVERSITARIA DE CIENCIAS DE LA SALUD HOSPITAL DE SAN JOSE}

Personería Jurídica No. 10917 del 01-12-1976 Resolución Ministerio de Educación Nacional No. 0125

Facultad de Instrumentación Quirúrgica

Código ICFES 270246100281100111100

Título otorgado

Instrumentador Quirúrgico
Oficina de admisiones: Calle 10 No. 18-75 Edificio docente, $\jmath^{\text {er }}$ piso PBX. 5998977 • 5998842 TFLEFAX $2019867 \cdot 2018938$

E-mail: instrumentacion@fucsalud.edu.co

hppt: www.fucsalud.edu.co

\begin{tabular}{|c|c|c|c|c|c|c|c|}
\hline I SEMESTRE & II SEMESTRE & III SEMESTRE & IV SEMESTRE & V SEMESTRE & VI SEMESTRE & VII SEMESTRE & VIII SEMESTRE \\
\hline $\begin{array}{l}\text { - Biología } \\
\text { - Morfofisiología I } \\
\text { - Física } \\
\text { - Química } \\
\text { - Introducción a la } \\
\text { instrumentación } \\
\text { - Comunicación } \\
\text { oral y escrita } \\
\text { - Informática }\end{array}$ & $\begin{array}{l}\text { - Microbiología } \\
\text { - Ecología } \\
\text { - Morfofisiología II } \\
\text { - Esterilización } \\
\text { - Bioquímica } \\
\text { - Técnicas } \\
\text { quirúrgicas I } \\
\text { - Técnicas de } \\
\text { instrumentación } \\
\text { - Sociología }\end{array}$ & $\begin{array}{l}\text { - Patología I } \\
\text { - Cuidados básicos } \\
\text { en salud } \\
\text { - Estadística } \\
\text { - Farmacología } \\
\text { - Anestesia } \\
\text { - Técnicas } \\
\text { quirúrgicas II } \\
\text { - Técnicas de } \\
\text { instrumentacion II } \\
\text { - Inglés I } \\
\text { - Psicología }\end{array}$ & $\begin{array}{l}\text { - Patología II } \\
\text { - Epidemiología } \\
\text { - Técnicas } \\
\text { quirúrgicas III } \\
\text { - Técnicas de } \\
\text { instrumentación II } \\
\text { - Inglés II } \\
\text { - Constitucion } \\
\text { política } \\
\text { y derecho en salud } \\
\text { - Ética general } \\
\text { - Administración } \\
\text { general } \\
\text { - Investigación I }\end{array}$ & $\begin{array}{l}\text { - Práctical } \\
\text { - Bioética } \\
\text { - Administración } \\
\text { hospitalaria } \\
\text { - Investigación II }\end{array}$ & $\begin{array}{l}\text { - Práctica ll } \\
\text { - Investigación II } \\
\text { - Didáctica } \\
\text { - Proyecto de } \\
\text { Investigación }\end{array}$ & $\begin{array}{l}\text { - Práctica III } \\
\text { - Proyecto de } \\
\text { Investigación } \\
\text { - Mercadeo } \\
\text { - Seminario de } \\
\text { Investigación }\end{array}$ & - Práctica IV \\
\hline
\end{tabular}

